\title{
Ülkelerin Ekonomik Performansı Üzerinde Regülasyonun Etkileri: Bir Dinamik Panel Veri Analizi
}

\author{
The Impact of Regulation on Economic Performance of the Countries: \\ A Dynamic Panel Data Analysis
}

\section{Prof. Dr. Kemal Yıldırım - Yrd. Doç. Dr. S. Fatih Kostakoğlu}

\section{Öz}

Regülasyonların ekonomik birimlerin kararları üzerinde önemli etkileri vardır. Dolayısıyla, regülasyonlar ülkelerin gösterdikleri ekonomik performans farkllikk larının bir sebebi olarak gösterilebilir. Bu çalışmanın temel amaci ülkelerarasindaki ekonomik performans farklilıklarının araștırılmasında regülasyonların rolünü ortaya koymaktır. Çalışmada analiz için dinamik panel veri modellerinden faydalanilmıştır ve örneklem olarak ise OECD ülkeleri seçilmiştir. Elde edilen bulgular, piyasa yanlıs regülasyonlarn ekonomik performans üzerinde olumlu etkisi olduğu yönünde iken aksine piyasa yanlist olmayan regülasyonlarm ise ekonomik performans üzerinde olumuz etkisi olduğu yönündedir.

Anahtar Kelimeler: Regülasyon, Dinamik Panel Veri Analizi, Ekonomik Performans

\begin{abstract}
Regulations have an important effects on the decisions of economic units. Thus, regulation as a one of the reason of differences in economic performance can be displayed. Main purpose of this study reveals role of regulation on the investigation of differences of economic performance among countries. In the study, it is used dynamic panel data models for analysis and is selected OECD countries as a sample. Findings of the study, while market supporter regulations have a positive effect on the economics performance, on the contrary non-market supporter regulations have a negative effect on the economic performance.
\end{abstract}

Keywords: Regulation, Dynamic Panel Data Analysis, Economic Performance

\section{Giriş}

İktisat literatüründe regülasyon kavramı sıklıkla ekonomik anlamda gerçekleştirilen düzenlemeler şeklinde anlaşılmaktadır. Ancak regülasyon kavramı düzenleme faaliyetlerinin yanında denetleme, yönetme ve yönlendirme faaliyetlerini de içeren oldukça geniş bir kavramdır. Dolayısıyla, regülasyonlar devlet tarafından ekonomik aktivite düzeyini etkilemek için kullanılan ve politik olarak da etkin bir araçtır. Nitekim bu yolla ekonominin üretebileceği toplam çıktı yani büyüme etkilenmektedir.

Regülasyonlar iki açıdan ele alınabilir. Bunlardan ilki doğrudan kısıtlayıcı regülasyon faaliyetlerdir. Bir başka deyişle doğrudan kısıtlayıcı regülasyonlar piyasada var olan ekonomik birimlerin kararlarına doğrudan müdahale eden ve kısıtlayan politik uygulamalardır. Bunlar, kredi piyasaları için bankaların kredi verme kararlarının ve faiz oranlarının kısıtlanması; emek piyasası için minimum ücret, iş akdini sonlandırmaya yönelik düzenlemeler; reel piyasa için ise fiyatların belirlenmesi, piyasaya girişlerin kısıtlanması gibi uygulamalardır. Diğeri ise piyasanın etkin çalışmasını tesis edici piyasa yanlısı regülasyon uygulamalarıdır. Bunlar ise ekonomik birimlerin karar alma sürecinde hukuksal koruma altında olması yani hukukun üstün kılınması, ekonomik birimlerin sahip olduğu mülklerin ve bu mülklerden doğan haklarının korunması, sözleşmelerin hukuksal garanti altına alınması vb. uygulamalardır.

Prof. Dr. Kemal Yıldırım, Anadolu Üniversitesi İ̈BF, kyildirim@anadolu.edu.tr Yrd. Doç. Dr. S. Fatih Kostakoğlu, Anadolu Üniversitesi AÖF, sfkostakoglu@anadolu.edu.tr

* Bu çalışma Anadolu Üniversitesi Sosyal Bilimler Enstitüsü İktisat Anabilim Dalında Doktora Tezi olarak yapılan "Regülasyon ve Büyüme” başlıklı çalışmadan türetilmiştir. 


\section{Literatür}

Ekonomik performansın bir ölçüsü olarak büyüme literatürüne bakıldığında ülkeler arasındaki gelir düzeyindeki farklılıkları açıklamada birçok değişken ele alınmıştır. Ancak literatürde regülasyon kavramı çokça ele alınmamıştır. Bunun yanında regülasyonların ülkeler arasındaki ekonomik farklılıkları açıklamada önemli bir faktör olduğunu belirten çalışmalarda mevcuttur (Loayza vd., 2005; Dawson, 2006:490). Djankov vd. (2006), ampirik literatürde ülkeler arasındaki büyüme farklılıklarını açıklamada regülasyonların diğer değişkenlere göre daha tutarlı olduğu- nu belirtmişlerdir. Bu bağlamda, bazı regülasyonlar piyasa yanlısıdır ve piyasanın etkin işlemesini sağlamaya yöneliktir. Dolayısıyla bu tarz regülasyon politikaları büyümeyi olumlu etkilerken, bunların tam tersi regülasyonların büyümeyi olumsuz etkilemesi beklenir. Nitekim Krol ve Svorny (1994:55) piyasada kısıtlayıcı etkileri olan regülasyonların piyasada faat liyet gösteren firmaların maliyetlerini artıracağını ve rekabeti kısıtlayacağını belirtmişlerdir. Dolayısıyla bu durumda büyüme bundan olumsuz etkilenecek ve işsizlik artacaktır. Literatürde bu konu üzerine yapılan ampirik çalışmaları bir tablo ile sunabiliriz.

Tablo 1. Literatürdeki Çalışmalar

\begin{tabular}{|c|c|c|}
\hline Araştırmacılar & Araştırma Konusu & $\begin{array}{l}\text { Araştırma } \\
\text { Sonucu }\end{array}$ \\
\hline $\begin{array}{lll}\text { Jorgenson } & \text { ve } & \text { Wilcoxen } \\
(1990) & & \end{array}$ & Çevresel regülasyonlar ve Büyüme & Negatif İlişki \\
\hline Koedijk vd. (1996) & $\begin{array}{l}\begin{array}{l}\text { Regülasyonlar ve } \\
\text { performans }\end{array} \\
\end{array}$ & Negatif İlişki \\
\hline Clague vd. (1999) & $\begin{array}{l}\text { Sözleşmelerin güvence altına } \\
\text { alınması ve mülkiyet haklarının } \\
\text { tanınması ve geliştirilmesi ile } \\
\text { ekonomik büyüme }\end{array}$ & Pozitif İlişki \\
\hline Levine (1999) & $\begin{array}{|lcr|}\text { Finansal aracı } & \text { kurumların } & \text { etkin } \\
\text { çalışması } & \text { için } & \text { gereken } \\
\text { regülasyonlar } & \text { ve } & \text { ekonomik } \\
\text { performans } & & \end{array}$ & Pozitif İlişki \\
\hline De Serres vd. (2006) & $\begin{array}{l}\text { Finansal sistemdeki gelişmeler ve } \\
\text { bu yöndeki regülasyonlar ile } \\
\text { ekonomik performans }\end{array}$ & Pozitif İlişki \\
\hline Loayza vd. (2005) & $\begin{array}{l}\text { Emek ve ürün piyasaları üzerinde } \\
\text { ağır yük oluşturan regülasyonlar ve } \\
\text { ekonomik performansı }\end{array}$ & Negatif İlişki \\
\hline Djankov vd. (2006) & $\begin{array}{|lrr|}\text { Reel piyasa } & \text { faaliyetlerini } \\
\text { kolaylaştırıcı } & \text { regülasyonlar } & \text { ve } \\
\text { büyüme } & & \end{array}$ & Pozitif İlişki \\
\hline Dawson (2006) & \begin{tabular}{lll|}
$\begin{array}{l}\text { Regülasyonlar } \\
\text { büyüme }\end{array}$ & ve & ekonomik \\
\end{tabular} & Pozitif İlişki \\
\hline Jalilian vd. (2007) & $\begin{array}{l}\text { Nitelikli regülasyonlar } \\
\text { ekonomik büyüme }\end{array}$ & Pozitif İlişki \\
\hline
\end{tabular}


Ekonomik Büyüme Alanında Etkin Bir Model: Mankiw, Romer ve Weil Modeli

Ekonomik performansın ampirik olarak analiz edilmesinde seçilen parametreler genellikle belirli bir büyüme modelinde ortaya koyulan değişkenlerdir. Literatürde sıklıkla kullanılan ve ampirik olarak güçlü sonuçlar üreten Solow model sıklıkla araştırmacılar tarafından tercih edilmektedir. Solow (1956) modelde toplam üretim fonksiyonu:

$\mathrm{Y}(\mathrm{t})=\mathrm{F}(\mathrm{K}(\mathrm{t}), \mathrm{L}(\mathrm{t}) ;$ Teknoloji)

şeklindedir. Ancak bu modelin bazı eksiklikleri vardır. Bu bağlamda; Solow modelin eksiklerini gideren ve modele beşeri sermayeyi de dahil ederek büyüme analizlerinde kullanılabilecek daha etkin bir model Mankiw, Romer ve Weil model tarafından ortaya konulmuştur (Nonneman ve Vanhoudt, 1996:943). Bu model ülkeler arasındaki kişi başına gelir farklılıklarının kaynağının fiziksel sermaye ve teknoloji yanında beşeri sermayeye de bağlı olduğunu ortaya koymuştur (Acemoglu, 2009: 85). Beşeri sermayeyi de büyümenin bir faktörü olarak gören bu modelin toplam üretim fonksiyonu:

$\mathrm{Y}(\mathrm{t})=\mathrm{F}(\mathrm{K}(\mathrm{t}), \mathrm{L}(\mathrm{t}), \mathrm{H}(\mathrm{t}) ;$ Teknoloji)

$H(t)$ : Beşeri Sermaye

olarak ifade edilir. $t$ ifadesi değişkenlerin zamanla değiştiğini göstermek için kullanılmıştır. Ekonomik performansın açıklanmasında beşeri sermayeyi de içeren bu modelin kullanılması, regülasyonların ekonomik performansa etkilerinin araştırılması noktasında daha net sonuçların elde edilmesini sağlayacaktır. Dolayısıyla bu çalışmada regülasyonların ekonomik performans üzerindeki etkileri analiz edilirken kullanılacak parametreler Mankiw, Romer ve Weil (1992) modeline göre belirlenecektir.

\section{Dinamik Panel Veri Analizi ve GMM Tahmincileri}

Araştırmalara konu olan birçok ekonomik ilişki statik olabileceği gibi dinamik bir süreç tarafından da belirleniyor olabilir. Panel veri analizi statik süreçlere uygulanabilirken dinamik süreçlerin analizi içinde uygulanabilmektedir. Bu amaçla geliştirilen dinamik panel veri modelleri mevcuttur. Bağımlı değişkenin gecikmeli değerini içerecek şekilde bir dinamik panel veri modeli şu şekilde yazılabilir:

$\mathrm{y}_{\mathrm{it}}=\mathrm{x}_{\mathrm{it}}^{\prime} \beta+\Theta \mathrm{y}_{\mathrm{i}, \mathrm{t}-\mathrm{t}}+\mathrm{c}_{\mathrm{i}}+\varepsilon_{\mathrm{it}}(1)$
Ancak bu şekilde bir denklem formülasyonu önemli bir soruna sahiptir. Modele dahil edilen bağımlı değişkenin gecikmeli değeri birleşik hata terimi $\delta_{\mathrm{it}}=$ $c_{i}+\varepsilon_{i t}$ ile ilişkilidir. Bunun temel nedeni kesitlere özgü heterojenliği ifade eden $c_{i}^{\prime}$ 'nin her bir grubun her bir gözlemi için aynı olmasıdır. Literatürde güncel olarak kullanılan ve popüler olan yöntem Genelleşterilmiş Momentler Yöntemi (GMM)[Arellano ve Bond (1991) ve Arellano ve Bover (1995)] tahmincileridir (Greene, 2012:497).

Arellano-Bond ve Arellano-Bover tahmincileri;

- Kısa zaman periyotları ve kesit sayısının büyük olduğu paneller (küçük T ve büyük $\mathrm{N}$ )

- Lineer fonksiyonel ilişkinin varlığı

- Dinamik süreçlerde yani bağımlı değişkenin güncel değerinin geçmiş değerlerine bağlı olduğu durumlar

- Bağımsız değişkenlerin katı dışsal olmadığı durumlar

- Kesitlere özgü heterojenliğin varllğg

- Kesite özgü otokorelasyon ve değișen varyans varlığında ancak kesitler arasında var olmadığ 1

durumlarda kullanılabilir (Roodman, 2009:86).

\section{Kesitlere Özgü Heterojenliğin Ortadan Kaldırılması}

Birleşik hatalarla açıklayıcı değişkenler arasında bir ilişkinin varllğı yani içsellik problemi en küçük kareler tahmincisinin tutarsiz (Roodman, 2009:101) ve sapmalı olmasina neden olur (Baltagi, 2008:147). Denklem(1)'in en küçük kareler ile tahmin edilmesindeki temel problem $y_{i, t-1}$ 'in $\delta_{i t}$ içindeki kesite özgü heterojenite ile ilişkili olmasıdır. Dolayısıyla yapılması gereken ilk iş bu kesite özgü heterojeniteyi ortadan kaldırmak olacaktır.

Kesitlere özgü heterojenlik terimi modelin genellikle birinci fark alınarak ortadan kaldırılmaktadır.

$\mathrm{y}_{\mathrm{it}}-\mathrm{y}_{\mathrm{i}, \mathrm{t}-1}=\left(\mathrm{x}_{\mathrm{it}}-\mathrm{x}_{\mathrm{i}, \mathrm{t}-1}\right)^{\prime} \beta+\Theta\left(\mathrm{y}_{\mathrm{i},-1-1}-\mathrm{y}_{\mathrm{i},-\mathrm{-}-2}\right)+\left(\varepsilon_{\mathrm{it}}-\varepsilon_{\mathrm{i}, \mathrm{t}-1}\right)$

ya da model fark operatörü yardımıyla gösterimi şu şekilde ifade edilebilir:

$$
\Delta \mathrm{y}_{\mathrm{it}}=\left(\Delta \mathrm{x}_{\mathrm{it}}\right)^{\prime} \beta+\Theta\left(\Delta \mathrm{y}_{\mathrm{i}, \mathrm{t}-\mathrm{t}}\right)+\left(\Delta \varepsilon_{\mathrm{it}}\right)
$$


Ancak dikkat edilirse model hala problemlidir. Birinci farkın alınması sonrasında modelde MA(1) şeklinde olan hata terimi ile gecikmeli bağımlı değişken arasındaki ilişki devam etmektedir. Dolayısıyla bu sorunu ortadan kaldırmak için iki dönüşüm önerilmektedir: Arellano ve Bond (1991) ve diğeri ise Arellano ve Bover (1995).

\section{Arellano ve Bond GMM Tahmincisi}

Bu tahminci Arellano ve Bond (1991) tarafindan önerilen Genelleştirilmiş Momentler Tahmincisidir (GMM). Denklem (2) modelin birinci farkının alınması ile kesite özgü etkiler ortadan kaldırılmış ancak açıklayıcı değiş̧ken olan $\mathrm{y}_{\mathrm{i}, \mathrm{t}-1}-\mathrm{y}_{\mathrm{i}, \mathrm{t}-2}$ ile hata terimi $\varepsilon_{\mathrm{it}}-\varepsilon_{\mathrm{i}, \mathrm{t}-1}$ ile hala ilişkilidir yani ortogonal değildirler. Bu ilişki $\mathrm{y}_{\mathrm{i}, \mathrm{t}-\mathrm{i}}$ ile $\varepsilon_{\mathrm{i}, \mathrm{t}-\mathrm{1}}$ arasındaki korelasyondan kaynaklanmak- tadır. Arellano ve Bond, denklem (2) de verilen farkı alınmış modelin araç değişken matrisi vasıtasıyla dönüştürülmesini ve ardından bu dönüştürülmüş modelin genelleştirilmiş en küçük kareler tahmincisi kullanılarak tahmin edilmesini önermişlerdir. $\mathrm{Bu}$ nedenle Genelleştirilmiş Momentler Tahmincisi “İki Aşamalı Araç Değişkenler Tahmincisi” olarak bilinmektedir (Tatoğlu, 2012:80).

Denklem (1)'de sunulan bir modeli ele alalım. Tüm $\mathrm{x}_{\mathrm{it}}$ ile c $\mathrm{c}_{\mathrm{i}}^{\prime}$ nin ilişkili olduğu ve $\mathrm{E}\left(\mathrm{x}_{\mathrm{it}} \varepsilon_{\mathrm{is}}\right)=0$ tüm $\mathrm{t}$ ve s'ler için geçerli olduğu durumda, modeldeki $x_{\mathrm{it}}$ katı dışsal değişkenlerin hepsi tüm denklemler için geçerli araç değişkenler olurlar (Arellano ve Bond, 1991:280). Araç değişken matrisini gösterirsek;

$$
P_{i}=\left[\begin{array}{cccc}
{\left[y_{i 1}, x_{i 1}^{\prime}, \ldots, x_{i T}^{\prime}\right]} & & 0 \\
& {\left[y_{i 1}, y_{i 2}, x_{i 1}^{\prime}, \ldots, x_{i T}^{\prime}\right]} & & \\
& 0 & \\
0 & & & {\left[y_{i 1}, \ldots, y_{i T-2}, x_{i 1}^{\prime}, \ldots, x_{i T}^{\prime}\right]}
\end{array}\right]
$$

Araç değiş̧kenler ile dönüştürülmüş birinci fark modeli matris formunda şöyledir:

$\mathrm{P}^{\prime} \Delta \mathrm{y}=\mathrm{P}^{\prime}\left(\Delta \mathrm{y}_{-1}\right) \Theta+\mathrm{P}^{\prime}(\Delta \mathrm{X}) \beta+\mathrm{P}^{\prime}(\Delta \varepsilon)(5)$
$\Delta \mathrm{X}, \Delta \mathrm{x}_{\mathrm{it}}$ bulunan gözlemlerin $\mathrm{N}(\mathrm{T}-2) \mathrm{K}$ olacak şekilde yığınlandığı bir matristir. Buradan Genelleştirilmiş Momentler Tahmincisi matrislerle gösterirsek:

$$
\left(\begin{array}{l}
\hat{\Theta} \\
\hat{\beta}
\end{array}\right)=\left(\left[\Delta \mathrm{y}_{-1}, \Delta \mathrm{X}\right]^{\prime} \mathrm{P}\left(\mathrm{P}^{\prime} \hat{\Omega} \mathrm{P}\right)^{-1} \mathrm{P}^{\prime}\left[\Delta \mathrm{y}_{-1}, \Delta \mathrm{X}\right]\right)^{-1}\left(\left[\Delta \mathrm{y}_{-1}, \Delta \mathrm{X}\right]^{\prime} \mathrm{P}\left(\mathrm{P}^{\prime} \hat{\Omega} \mathrm{P}\right)^{-1} \mathrm{P}^{\prime} \Delta \mathrm{y}\right)(6)
$$

$\hat{\Omega}$ hata terimlerinin varyans-kovaryans matrisini ifade eder. Eğer $x_{\text {it }}{ }^{\prime} l e r$ önceden belirlenmiş değişkenler ise $\mathrm{E}\left(\mathrm{x}_{\mathrm{it}} \varepsilon_{\mathrm{is}}\right)=0 \mathrm{~s}<\mathrm{t}$ ve tam tersi için sıfır olması durumunda $\left[\mathrm{x}_{\mathrm{i} 1}^{\prime}, \ldots, \mathrm{x}_{\mathrm{i}(\mathrm{s}-1)}^{\prime}\right]$ s periyotu için fark denkleminde geçerli araç değişken olarak kullanılabilirler (Arellano ve Bond, 1991:280). Buran dan araç değişkenler matrisi şu şekilde gösterilebilir (Baltagi, 2008:152):

$$
P_{i}=\left[\begin{array}{c}
{\left[y_{i 1}, x_{i 1}^{\prime}, x_{i 2}^{\prime}\right]} \\
0 \\
0
\end{array}\right]
$$


Araç değişken matrisi iki uç durumda gösterilmiştir. Ancak bazı durumlarda hem önceden belirlenmiş değişkenler hem de katı dıșsal değișkenlerin kombinasyonu birlikte olabilir. Bu durumda araç değișken matrisi ona göre düzeltilmelidir. Bununla birlikte $\mathrm{x}_{\mathrm{it}}$ 'lerin bazıları $c_{i}$ ile ilişkili iken bazıları olmayabilir (Baltagi, 2008:152).

Arellano ve Bond tarafından önerilen yöntem bazı zayıflıklara sahiptir. Özellikle dengesiz panellerde kesitlerde bulunan veri eksikliklerini daha da artırmaktadır (Roodman, 2009:104). Bununla birlikte, modelde gecikmeli değişkenlerin sayısının fazla olması ve kesitlere özgü heterojenitenin sahip olduğu varyansın hatanın sahip olduğu varyansa olan oranının büyük olması durumlarında da bu tahminci yetersiz kalmaktadır. Bu durumların varlığında Arellano ve Bover ortogonal sapmalar tahmincisi önerilir.

\section{Arellano ve Bover GMM Tahmincisi}

Dinamik panel veri modellerinde birinci fark dönüşüm yönteminin bazı dezavantajlarından ötürü, Arellano ve Bover etkin araç değişken tahmincisinin elde edilmesinde ortogonal sapmalar yöntemini önermişlerdir. Ortogonal sapmalar yöntemi, birinci farklar yönteminde yapılan cari gözlemlerden önceki dönem gözlemleri çıkarmak yerine değişkenin erişilebilir tüm gelecekteki değerlerinin ortalamalarının çıkarılmasını önerir. Veri setlerinde elde edilemeyen gözlemlerin olmaması bu durumda önemli olmayacaktır. Her bir kesitin sonuncu gözlemi hariç tüm gözlemler için türetim yapılabilecektir. Dolayısıyla gecikmeli gözlemler dönüşüme dahil olmadığından bunlar araç değişken olarak kullanılabilecektir. Her bir değişken için dönüşümü göstermek istersek, $r$ bir değişken olsun:

$$
\mathrm{r}_{\mathrm{i}, \mathrm{t}+1}^{\perp}=\mathrm{W}_{\mathrm{it}}\left(\mathrm{r}_{\mathrm{it}}-\frac{1}{\mathrm{~T}_{\mathrm{it}}>\mathrm{t}} \sum_{\mathrm{it}}\right)(8)
$$

dönüşüm bu eşitliğe göre gerçekleşir ve burada $\mathrm{w}_{\mathrm{it}}$ ölçek faktörüdür (Roodman, 2009:104). Buradan bir statik panel veri modeli tanımlarsak:

$$
\mathrm{y}_{\mathrm{it}}=\mathrm{x}_{\mathrm{it}}^{\prime} \beta+\mathrm{Z}_{\mathrm{i}} \mathrm{Y}+\delta_{\mathrm{it}}(9)
$$

$\mathrm{Z}_{\mathrm{i}}$ zamanla değişmeyen değişkenlerden, $\mathrm{x}_{\mathrm{it}}$ ise hem zamana hem de kesitlere göre değișen değișkenlerden oluşmaktadır. Bu ifade daha kullanışlı olacak şekilde vektör formunda gösterilirse (Tatoğlu, 2012:86):

$$
\mathrm{y}_{\mathrm{i}}=\mathrm{J}_{\mathrm{i}} \mathrm{h}+\delta_{\mathrm{i}}(10)
$$

burada $\mathrm{y}_{\mathrm{i}}=\left(\mathrm{y}_{\mathrm{i} 1}, \ldots, \mathrm{y}_{\mathrm{iT}}\right)^{\prime}, \delta_{\mathrm{i}}=\left(\delta_{\mathrm{i} 1}, \ldots, \delta_{\mathrm{iT}}\right)^{\prime}, \mathrm{h}^{\prime}=\left(\beta^{\prime}, \mathrm{Y}^{\prime}\right), \mathrm{J}_{\mathrm{i}}=\left[\mathrm{X}_{\mathrm{i}}, 1_{\mathrm{t}} \mathrm{Z}_{\mathrm{i}}^{\prime}\right]$ ve $\mathrm{X}_{\mathrm{i}}=\left(\mathrm{x}_{\mathrm{i} 1}, \ldots, \mathrm{x}_{\mathrm{iT}}\right)^{\prime}$ ve $\mathrm{1}_{\mathrm{t}} \mathrm{T}$ boyutlu birler vektörüdür. Ek olarak modelin tek yönlü hata bileşenleri olduğu varsayllır ve $E\left[\delta_{\mathrm{i}} \delta_{\mathrm{i}}^{\prime} / \mathrm{j}_{\mathrm{i}}\right], \mathrm{x}_{\mathrm{i}}=\left(\mathrm{x}_{\mathrm{i} 1}^{\prime}, \ldots, \mathrm{x}_{\mathrm{iT}}^{\prime}\right)^{\prime}$ iken $\mathrm{j}_{\mathrm{i}}=\left(\mathrm{x}_{\mathrm{i}}^{\prime}, \mathrm{Z}_{\mathrm{i}}^{\prime}\right)^{\prime}$ ile bağımlı olarak kısıtlanmamış olacaktır. Arellano ve Bover (1995:32) (10)'daki denklem sistemini tekil olmayan TxT boyutlu $\mathrm{H}$ gibi bir matris aracilığıyla dönüştürür ve bu matris şu şekilde tanımlanır:

$$
H=\left[\begin{array}{c}
G \\
\imath_{T}^{\prime} / T
\end{array}\right]
$$

G, G.1 $1_{\mathrm{T}}=0$ şartını sağlayan (T-1) ranka sahip (T-1) x T boyutlu bir matristir. $\mathrm{G}$ birinci fark operatörü olabileceği gibi grup içi operatörün ilk (T-1) satırı da olabilir. Buradan dönüştürülmüş hatalar:

$$
\delta_{i}^{+}=H \delta_{\mathrm{i}}=\left[\begin{array}{c}
G \delta_{\mathrm{i}} \\
\bar{\delta}_{\mathrm{i}}
\end{array}\right]
$$

şeklindedir. İlk (T-1) dönüştürülmüş hata c c'den bağımsızdır yani $c_{i}^{\prime}$ yi içermez. Bundan dolayı dışsal değişkenlerin hepsi ilk (T-ı) denklem için geçerli araç değişkenlerdir (Baltagi, 2008:156). $\mathrm{m}_{\mathrm{i}}$ isimli bir mat- ris tanımlayalım. $\mathrm{Bu}$ matris $\mathrm{c}_{\mathrm{i}}$ ile ilişkisiz ve $\mathrm{j}_{\mathrm{i}}$ 'nin alt kümesi olduğunu varsayalım. Ek olarak, bu matrisin boyutunun $\mathrm{h}$ ile aynı ya da ondan büyük olduğu varsayılsın. Böylece $m_{i}, X_{1}$ ve $Z_{1}$ dışsal değişkenler setini içerir ve $\left[Z_{1, i}^{\prime}, x_{1, i 1}^{\prime}, \ldots, x_{1, i T}^{\prime}\right]^{\prime}$ gibi bir matrise dayanır (Baltagi, 2008:156). Buradan, bütünüyle dönüştürülmüş bir sistem için geçerli araç değişken matrisi;

$$
M_{i}=\left[\begin{array}{cccc}
j_{i}^{\prime} & & & 0 \\
& 0 & & \\
& & j_{i}^{\prime} & \\
0 & & & m_{i}^{\prime}
\end{array}\right]
$$


şeklinde açık bir şekilde gösterilir. Moment koşulu ise, $\mathrm{E}\left(\mathrm{M}_{\mathrm{i}}^{\prime} \mathrm{H} \delta_{\mathrm{i}}\right)=0$ şeklinde sunulabilir. Bunula birlikte, $\overline{\mathrm{H}}=\mathrm{I}_{\mathrm{N}} \otimes \mathrm{H}$ ve $\hat{\Omega}=\mathrm{I}_{\mathrm{N}} \otimes \Omega \quad$ gibi iki ifade tanımlanabilir. Buradan denklem (10)'daki her bir terim önden $\mathrm{M}^{\prime} \overline{\mathrm{H}}$ ile önden çarparsak(Tatoğlu, 2012:87);
$\mathrm{M}^{\prime} \overline{\mathrm{H}} \mathrm{y}_{\mathrm{i}}=\mathrm{M}^{\prime} \overline{\mathrm{H}} \mathrm{J}_{\mathrm{i}} \mathrm{h}+\mathrm{M}^{\prime} \overline{\mathrm{H}} \delta_{\mathrm{i}}(14)$

elde edilir. Bu nihai denklemin genelleştirilmiş en küçük kareler yöntemi ile tahmininden Arellano ve Bover (1995:33) tahmincisi elde edilir Buradan hareketle, $\mathrm{h}$ şöyle tahmin edilmektedir:

$$
\hat{\mathrm{h}}=\left[\mathrm{J}^{\prime} \overline{\mathrm{H}}^{\prime} \mathrm{M}\left(\mathrm{M}^{\prime} \overline{\mathrm{H}} \hat{\Omega}^{+} \overline{\mathrm{H}}^{\prime} \mathrm{M}\right)^{-1} \mathrm{M}^{\prime} \overline{\mathrm{H}} \mathrm{J}\right]^{-1} \mathrm{~J} \overline{\mathrm{H}}^{\prime} \mathrm{M}\left(\mathrm{M}^{\prime} \overline{\mathrm{H}} \hat{\Omega}^{+} \overline{\mathrm{H}}^{\prime} \mathrm{M}\right)^{-1} \mathrm{M}^{\prime} \overline{\mathrm{H}} \mathrm{y}
$$

burada

$$
J=\left(J_{1}^{\prime}, \ldots, J_{N}^{\prime}\right)^{\prime}, y=\left(y_{1}^{\prime}, \ldots, y_{N}^{\prime}\right)^{\prime} \text { ve } M=\left(M_{1}^{\prime}, \ldots, M_{N}^{\prime}\right)^{\prime}
$$

şeklinde gösterilebilir. Pratik olarak elde edilen dönüştürülmüş sistemin varyans-kovaryans matrisi $\hat{\Omega}^{+}=\mathrm{H} \Omega \mathrm{H}^{\prime}$ kullanılmaz. Bunun yerine tutarlı tahminci varyans-kovaryans matrisi kullanılır:

$$
\hat{\Omega}^{+}=\frac{\sum_{\mathrm{i}=1}^{\mathrm{N}} \hat{\mathrm{u}}_{\mathrm{i}}^{+}\left(\hat{\mathrm{u}}_{\mathrm{i}}^{+}\right)^{\prime}}{\mathrm{N}}
$$

$\hat{\mathrm{u}}_{\mathrm{i}}^{+}$tutarlı ilk tahminlere dayanan kalıntılardır. Sonuçta elde edilen $\hat{\mathrm{h}}$, verilen moment kısıtlarına dayanan sabit varyanslı h'in optimal GMM tahmincisidir (Baltagi, 2008:156). Denklem (9)'un sağ tarafına gecikmeli bağımlı değişkeni ekleyerek açıklamalarımıza devam edelim:

$$
\mathrm{y}_{\mathrm{it}}=\Theta \mathrm{y}_{\mathrm{i},-1-1}+\mathrm{x}_{\mathrm{it}}^{\prime} \beta+\mathrm{Z}_{\mathrm{i}} \Upsilon+\delta_{\mathrm{it}}
$$

Eğer $t=0$ gözlenebiliyorsa ve belirlenim sağlamak için yeteri kadar geçerli araç değişken varsa denklem (10)'da sunulan ifadeler revize edilmelidir. Yeniden ifade edersek, $\mathrm{h}^{\prime}=\left(\Theta, \beta^{\prime}, \mathrm{Y}^{\prime}\right), \mathrm{J}_{\mathrm{i}}=\left[\mathrm{y}_{\mathrm{i}(-1)}, \mathrm{X}_{\mathrm{i}}, \mathrm{1}_{\mathrm{t}} \mathrm{Z}_{\mathrm{i}}^{\prime}\right]$ ve $\mathrm{y}_{\mathrm{i}(-\mathrm{l})}=\left(\mathrm{y}_{\mathrm{i}, 1}, \ldots, \mathrm{y}_{\mathrm{i}, \mathrm{T}-1}\right)^{\prime}$

şeklinde gösterilebilir. Bu koşullar altında (15) ifae desinde gösterilen GMM tahmincisi bu model içinde hala tutarlıdır (Baltagi, 2008:157). $\mathrm{y}_{\mathrm{i}(1)}$ 'in önceden belirlenmiş değişken olarak ele alınması durumunda ortaya çıkacak ortogonalite kıstları, önceki gerekliliklere ek olarak dönüşüm matrisi G’nin üst üçgensel olması sağlanarak (15) ifadesinde gösted rilen tahminci ile kolaylıkla birleştirilecektir. G üst üçgensel ve $\delta_{i t}$ 'nin otokorelasyon içermemesi durumunda, periyot $t$ için ifade olunan denklemden ki dönüştürülmüş hatalar $\mathrm{c}_{\mathrm{i}} \mathrm{ve}\left(\varepsilon_{\mathrm{i} 1}, \ldots, \varepsilon_{\mathrm{i}(\mathrm{t}-1)}\right)$ 'den bağımsızdır yani ilişkisizdir. Böylece $\left(\mathrm{y}_{\mathrm{i} 0}, \ldots, \mathrm{y}_{\mathrm{i}, \mathrm{t}-1}\right)$ bu denklem için geçerli ilave araçlar olurlar. Araç değişken matrisi de bu yeni tanımlamalara göre düzenlenmelidir:

$$
\mathrm{M}_{\mathrm{i}}=\left[\begin{array}{ccccc}
\left(\mathrm{j}_{\mathrm{i}}^{\prime}, \mathrm{y}_{\mathrm{io}}\right) & & & & 0 \\
& \left(\mathrm{j}_{\mathrm{i}}^{\prime}, \mathrm{y}_{\mathrm{io}}, \mathrm{y}_{\mathrm{il}}\right) & & & \\
& & 0 & & \\
& & & \left(\mathrm{j}_{\mathrm{i}}^{\prime}, \mathrm{y}_{\mathrm{io}}, \ldots, \mathrm{y}_{\mathrm{i}, \mathrm{T}-2}\right) & \\
0 & & & & \mathrm{~m}_{\mathrm{i}}^{\prime}
\end{array}\right]
$$

Araç değişken matrisi olarak (18)'i kullanan GMM tahmincisi G’nin gerekli koşulları sağlaması durumunda G’nin seçimi ile değişmez (Arellano ve Bover, 1995: 39-40).

\section{Sargan Aşırı Belirlenim Kısıtları Testi}

GMM tahmincileri vasıtasıly yapılan dinamik panel veri modeli tahminlerde kullanılan araçların geçerliliği test edilmelidir. Bu durumu test etmek için Sargan aşırı belirlenim kısıtları istatistiğini kullanabiliriz. Araç değişken matrisini $\mathrm{P}$ ile ifade edersek, bu test istatistiği şöyle olacaktır:

$$
\mathrm{ST}=\Delta \hat{\delta}^{\prime} \mathrm{P}\left[\sum_{\mathrm{i}=1}^{\mathrm{N}} \mathrm{P}_{\mathrm{i}}^{\prime}\left(\Delta \hat{\delta}_{\mathrm{i}}\right)\left(\Delta \hat{\delta}_{\mathrm{i}}\right)^{\prime} \mathrm{P}_{\mathrm{i}}\right]^{-1} \mathrm{P}^{\prime}(\Delta \hat{\delta}) \sim \chi_{\mathrm{b}-\mathrm{K}-1}^{2}
$$

Alt indis b, araçlar matrisi P'nin sütun sayısını, $\Delta \hat{\delta}$ ise denklem (6)'da verilen iki aşamalı tahminden elde edilen kalıntıları ifade eder (Baltagi, 2008:153). 


\section{Veri Seti}

$\mathrm{Bu}$ çalışmada örneklem olarak OECD ülkeleri belire lenmiştir. Fakat ampirik analizlerde sıkça karşılaşılan bir durum olarak bazı ülkelerin verilerinin olmaması dolayısıyla bu ülkeler örneklemden dışlanmış ve geriye kalan 27 OECD ülkesi için analiz yapılmıştır. Analize konu ülkelerin 1975-2010 dönemini kapsayan verileri analizde kullanılmıştır. Örnekleme dahil olan 27 OECD ülkesi; Almanya, Amerika Birleşik Devletleri, Avusturalya, Belçika, Birleşik Krallık, Danimarka, Finlandiya, Fransa, Hollanda, İrlanda, İspanya, İsrail, İsveç, İsviçre, İtalya, İzlanda, Japonya, Kanada, Kore Cumhuriyeti, Lüksemburg, Meksika, Norveç, Portekiz, Şili, Türkiye, Yunanistan ve Yeni Zelanda'dır.

Tablo 2. Veri Tanımları

\begin{tabular}{|c|c|c|}
\hline Veri & Elde Edilen Veri Tabanı & $\begin{array}{l}\text { Modeldeki } \\
\text { Kisaltması }\end{array}$ \\
\hline $\begin{array}{l}\text { Satın alma gücü paritesiyle kişi başına } \\
\text { GSYİH }\end{array}$ & $\begin{array}{l}\text { Heston, Summers ve Aten } \\
\text { (2012)- PENN World Table }\end{array}$ & LnRgdp \\
\hline $\begin{array}{l}\text { Satın alma gücü paritesiyle kişi başına } \\
\text { GSYİH'daki yatırımların payı }\end{array}$ & $\begin{array}{l}\text { Heston, Summers ve Aten } \\
\text { (2012)- PENN World Table }\end{array}$ & LnCap \\
\hline $\begin{array}{l}\text { Beşeri sermaye- } 15 \text { yaş ve üzeri ortaokulu } \\
\text { tamamlamış kişilerin nüfustaki payı }\end{array}$ & $\begin{array}{l}\text { Barro-Lee Education Data Set } \\
(2010)\end{array}$ & LnHCap \\
\hline Nüfusun büyüme oran1 ${ }^{2}$ & World Bank & $\operatorname{Ln}(\mathrm{n}+\mathrm{g}+\delta)$ \\
\hline $\begin{array}{c}\text { Kredi, Emek ve Reel Piyasa Regülasyonları } \\
\qquad \text { Endeksi }^{3}\end{array}$ & $\begin{array}{l}\text { Gwartney, Lawson ve Hall } \\
\text { (2012)- Economic Freedom of } \\
\text { the World by Fraiser Institute }\end{array}$ & $\mathrm{Rg}$ \\
\hline $\begin{array}{l}\text { Mülkiyet Haklarının Korunması ve Hukuki } \\
\qquad \text { Yapı Endeksi }\end{array}$ & $\begin{array}{l}\text { Gwartney, Lawson ve Hall } \\
\text { (2012)- Economic Freedom of } \\
\text { the World by Fraiser Institute }\end{array}$ & Lsspr \\
\hline
\end{tabular}

\section{Dinamik Panel Veri Analizi Tahmin Sonuçları}

İktisat literatüründe ele alınan birçok konu yapısı gereği dinamik bir süreci içermektedir. Doğal olarak büyüme konusu da dinamik bir süreçtir. Dolayısıyla regülasyonların ekonomik performans üzerindeki etkisi araştırılırken dinamik modellerle çalıșılması önemlidir. Bu amaçla, dinamik panel literatüründe sıklıkla kullanılan ve popüler olan Arellano-Bond (1991) ve Arellano-Bover (1995) GMM tahmincileri kullanılarak analiz sonuçları sunulacaktır.

1 Islam (1995) izlenilerek beş yıllık veri alınmış ve elde edilen veri seti için ise belirtilen yılın verisi kullanılmıştır.

2 Ancak bu değişken $(\mathrm{g}+\delta)$ da içermelidir. Ampirik büyüme literatüründe bu $(\mathrm{g}+\delta)$ değeri 0.05 kabul edilmektedir. Burada da $(\mathrm{g}+\delta)$ değeri 0.05 kabul edilerek analize dahil edilecektir.

3 Bu endeks 0 değerinden 10’a doğru gidildikçe daha az regülasyon daha fazla ekonomik özgürlüğü ifade eder. 
İlk olarak Mankiw, Romer ve Weil modelinde sunue lan ekonomik büyümenin belirleyicileri olan değişkenlere ek olarak model mülkiyet haklarının korunması ve hukuki yapı endeksi ile genişleterek tahmin yapılmıştır ve tablo 3'de hem Arellano-Bond hem de Arellano-Bover tahminci sonuçları sunulmuştur. İlk olarak büyümenin belirleyicileri olan değişkenlerin hepsi her iki modelde de tüm güven düzeylerinde anlamlı ve katsayıları beklentilerimizle uyumludur. Aynı şekilde her iki model içinde piyasa yanlısı re- gülasyonları temsil için sunulan mülkiyet haklarının korunması ve hukuki yapı endeksinin katsayısı burada pozitif ve bütün güven düzeylerinde anlamlı olarak elde edilmiştir. Bu da gösteriyor ki, piyasa yanlısı regülasyonların yani mülkiyet haklarının güvence altına alınması ve hukukun üstün kılınması halinde ekonomik performans bundan olumlu yönde etkilenmektedir. Modellerin tanımlayıcı istatistik sonuçları da modellerin tahmininde herhangi bir problem olmadığını göstermektedir.

Tablo 3. Piyasa Yanlısı Regülasyonlar ve Ekonomik Performans

\begin{tabular}{|c|c|c|c|c|}
\hline \multicolumn{5}{|c|}{ Bağımlı Değişken LnRgdp } \\
\hline & \multicolumn{2}{|c|}{$\begin{array}{l}\text { Arellano-Bond } \\
\text { Tahminci }\end{array}$} & \multicolumn{2}{|c|}{$\begin{array}{l}\text { Arellano-Bover } \\
\text { Tahminci }\end{array}$} \\
\hline Değişkenler & Katsayılar & p değeri & Katsayılar & p değeri \\
\hline LnRgdp(-1) & $0.727 * * *$ & 0.000 & $0.692^{* * *}$ & 0.000 \\
\hline LnCap & $0.311^{* * *}$ & 0.000 & $0.303^{* * *}$ & 0.000 \\
\hline \begin{tabular}{|l} 
LnHCap \\
\end{tabular} & $0.059^{* * *}$ & 0.009 & $0.095^{* * *}$ & 0.000 \\
\hline$\overline{\operatorname{Ln}(\mathrm{n}+\mathrm{g}+\delta)}$ & $-0.183^{* * *}$ & 0.002 & $-0.227 * * *$ & 0.000 \\
\hline Lsspr & $0.043 * * *$ & 0.000 & $0.039^{* * *}$ & 0.007 \\
\hline Gözlem Say1s1 & 162 & & 135 & \\
\hline Grup Sayıs1 & 27 & & 27 & \\
\hline Sargan Test $\mathrm{p}$ değeri & 0.27 & & 0.26 & \\
\hline
\end{tabular}

LnRgdp(-1) önceden belirlenmiş değişken olarak ele alınmıştır. LnCap, LnHCap ve $\operatorname{Ln}(\mathrm{n}+\mathrm{g}+\delta)$ içsel değişkenler olarak ele alınmıştır (Bond, Hoeffler ve Temple(2001)). Değişen varyans ve otokorelasyon sorunu White Düzeltmesi aracılığıyla dikkate alınmıştır. Aşırı belirlenimin tespiti (araç değişkenlerin geçerliliği) için Sargan test kullanılmıştır. Elde edilen sonuçlar aşırı belirlenim kısıtlarının (araç değişkenlerin) geçerli olduğunu gösterir. *, **, *** sırasıyla $\% 10, \% 5$ ve $\% 1$ anlam düzeylerini göstermektedir. 
Bir diğer tahmin sonuçları; Mankiw, Romer ve Weil modelinde sunulan ekonomik büyümenin belirleyicileri olan değişkenlere ek olarak model kredi, emek ve reel piyasa regülasyonları endeksi ile genişletilmiş ve modelin bu hali için tahmin yapılmıștır. Așağıda tablo 4'de hem Arellano-Bond hem de Arellano-Bover tahminci sonuçları sunulmuştur. İlk olarak büyümenin belirleyicileri olan değişkenlerin tamamı her iki model için tüm güven düzeylerinde anlamlı ve katsayıları da beklentilerimizle uyumludur. Benzer şekilde her iki model içinde doğrudan piyasaya müdahaleci regülasyonları gösteren değişkenin katsayısı pozitif bulunmuștur ve o da bütün güven düzeylerinde anlamlıdır. Ancak bu değişkenin değerinde meydana gelen artış daha fazla özgürlük yani daha az regülasł yonu ifade etmektedir. Dolayısıyla piyasalara üzerinde bulunan doğrudan müdahalenin azaltılması büyümeyi olumlu yönde etkilemektedir. Modellerin tanımlayıcı istatistik sonuçları da modellerin tahmininde herhangi bir problem olmadığını göstermektedir.

Tablo 4. Piyasa Yanlısı Olmayan Regülasyonlar ve Ekonomik Performans

\begin{tabular}{|c|c|c|c|c|}
\hline \multicolumn{5}{|c|}{ Bağımlı Değişken LnRgdp } \\
\hline & \multicolumn{2}{|c|}{$\begin{array}{l}\text { Arellano-Bond } \\
\text { Tahminci }\end{array}$} & \multicolumn{2}{|c|}{$\begin{array}{l}\text { Arellano-Bover } \\
\text { Tahminci }\end{array}$} \\
\hline Değişkenler & Katsayılar & $p$ değeri & Katsayılar & $\mathrm{p}$ değeri \\
\hline LnRgdp(-1) & $0.629 * * *$ & 0.000 & $0.738^{* * *}$ & 0.000 \\
\hline LnCap & $0.303^{* * *}$ & 0.000 & $0.264^{* * *}$ & 0.000 \\
\hline LnHCap & $0.056^{* * *}$ & 0.005 & $0.039 * * *$ & 0.005 \\
\hline $\operatorname{Ln}(\mathrm{n}+\mathrm{g}+\delta)$ & $-0.181^{* * *}$ & 0.002 & $-0.252^{* * *}$ & 0.000 \\
\hline$\overline{\mathrm{Rg}}$ & $0.060^{* * *}$ & 0.000 & $0.023^{* * *}$ & 0.000 \\
\hline Gözlem Sayısı & 162 & & 162 & \\
\hline Grup Sayı1 1 & 27 & & 27 & \\
\hline Sargan Test $p$ değeri & 0.63 & & 0.32 & \\
\hline
\end{tabular}

$\overline{\text { LnRgdp(-1) önceden belirlenmiş değişken olarak ele alınmıştır. LnCap, }}$ LnHCap ve $\operatorname{Ln}(\mathrm{n}+\mathrm{g}+\delta)$ içsel değişkenler olarak ele alınmıştır (Bond, Hoeffler ve Temple(2001)). Değişen varyans ve otokorelasyon sorunu White Düzeltmesi aracılığıyla dikkate alınmıştır. Aşırı belirlenimin tespiti (araç değişkenlerin geçerliliği) için Sargan test kullanılmıştır. Elde edilen sonuçlar aşırı belirlenim kısıtlarının ( araç değişkenlerin )geçerli olduğunu gösterir. *, **, *** sırasıyla $\% 10, \% 5$ ve $\% 1$ anlam düzeylerini göstermektedir. 
Tablo 5. Piyasa Yanlısı Olan ve Olmayan Regülasyonlar ve Ekonomik Performans

\begin{tabular}{|c|c|c|c|c|}
\hline \multicolumn{5}{|c|}{ Bağımlı Değişken LnRgdp } \\
\hline \multirow[b]{2}{*}{ Değişkenler } & \multicolumn{2}{|c|}{$\begin{array}{l}\text { Arellano-Bond } \\
\text { Tahminci }\end{array}$} & \multicolumn{2}{|c|}{$\begin{array}{l}\text { Arellano-Bover } \\
\text { Tahminci }\end{array}$} \\
\hline & Katsay1lar & p değeri & Katsayilar & p değeri \\
\hline LnRgdp(-1) & $0.632^{* * *}$ & 0.000 & $0.689^{* * *}$ & 0.000 \\
\hline LnCap & $0.318^{* * *}$ & 0.000 & $0.267^{* * *}$ & 0.000 \\
\hline LnHCap & $0.042^{*}$ & 0.059 & $0.070^{* * *}$ & 0.004 \\
\hline $\operatorname{Ln}(\mathrm{n}+\mathrm{g}+\delta)$ & $-0.121^{*}$ & 0.074 & $-0.213^{* * *}$ & 0.003 \\
\hline Lsspr & $0.037^{* * *}$ & 0.000 & $0.022^{* * *}$ & 0.006 \\
\hline$\overline{\mathrm{Rg}}$ & $0.049^{* * *}$ & 0.000 & $0.024 * *$ & 0.048 \\
\hline Gözlem Sayısı & 162 & & 162 & \\
\hline Grup Sayısı & 27 & & 27 & \\
\hline Sargan Test $p$ değeri & 0.53 & & 0.38 & \\
\hline \multirow{2}{*}{\multicolumn{5}{|c|}{$\begin{array}{l}\text { LnRgdp(-1) önceden belirlenmiş değişken olarak ele alınmıştır. LnCap, } \\
\text { LnHCap ve } \operatorname{Ln}(n+g+\delta) \text { içsel değişkenler olarak ele alınmıştır (Bond, } \\
\text { Hoeffler ve Temple(2001)). Değişen varyans ve otokorelasyon sorunu }\end{array}$}} \\
\hline & & & & \\
\hline \multirow{2}{*}{\multicolumn{5}{|c|}{$\begin{array}{l}\text { White Düzeltmesi aracılığıyla dikkate alınmıştır. Aşırı belirlenimin } \\
\text { tespiti (araç değişkenlerin geçerliliği) için Sargan test kullanılmıştır. } \\
\text { Elde edilen sonuçlar aşırı belirlenim kısıtlarının (araç değişkenlerin) }\end{array}$}} \\
\hline & & & & \\
\hline geçerli olduğunu gös & $* *, * *, * * *$ & sirasıyla & $010, \% 5$ ve & $\% 1$ anlam \\
\hline
\end{tabular}

Son olarak Mankiw, Romer ve Weil modelinde sunulan ekonomik büyümenin belirleyicileri olan değișkenlere hem kredi, emek ve reel piyasa regülasyonları endeksi ve hem de mülkiyet haklarının korunması ve hukuki yapı endeksi dahil edilerek elde edilen model için yapılan tahmin sonuçları yukarıdaki tablo 5'de gösterilmiştir. Tablo 5'de hem Arellano-Bond hem de Arellano-Bover tahminci sonuçları verilmiştir. İlk olarak büyümenin belirleyicileri olan değişkenlerden
Arellano-Bond tahmincisi için elde edilen sonuçlara göre $\operatorname{LnHCap}$ ve $\operatorname{Ln}(\mathrm{n}+\mathrm{g}+\delta) \% 10$ güven düzeyinde diğerleri ise tüm güven düzeylerinde anlamlıdır. Regülasyonların etkilerini ölçmek için kullanılan kredi, emek ve reel piyasa regülasyonları endeksi ve mülkiyet haklarının korunması ve hukuki yapı endeksi değişkenlerinin katsayıları yine tüm güven düzeylerinde anlamlıdır. Bu bağlamda, daha fazla özgürlük yani reel piyasa üzerindeki kısıtlayıcı yüklerin kal- 
dırılması ve mülkiyet haklarını güvence altına alan ve hukuki yapının gelişmesine katkı sağlayan regüle edici faaliyetlerin büyümeyi olumlu etkilediği söylenebilir. Arellano-Bover tahminci sonuçlarına göre ise, büyümenin belirleyicileri olan değişkenlerin tamamının tüm güven düzeylerinde anlamlı ve katsayılarının beklentilerimizle uyumlu olduğu görülmektedir. Doğrudan piyasaya müdahaleci regülasyonları gösteren kredi, emek ve reel piyasa regülasyonları endeksi değiş̧enin katsayısı pozitif bulunmuştur ve $\% 10$ ve $\% 5$ güven düzeylerinde anlamlıdır. Bunun yanında piyasa yanlısı regülasyonları ifade eden mülkiyet haklarının korunması ve hukuki yapı endeksinin katsayısı tüm güven düzeylerinde anlamlı ve pozitif bulunmuştur. Modellerin tanımlayıcı istatistik sonuçları da modelin tahmininde herhangi bir problem olmadığını göstermektedir. Dolayısıyla elde edilen bulgular, doğrudan kısıtlayıcı regülasyonları ifade eden kredi, emek ve reel piyasa regülasyonları endeksi katsayısının tüm tahmin sonuçlarında pozitif ve anlamlı bulunması daha az regülasyon daha fazla özgürlügün ekonomik performans üzerinde olumlu etkisi olacağını ortaya koyarken bununla birlikte piyasa yanlısı regülasyonları ifade için kullanılan mülkiyet haklarının korunması ve hukuki yapı endeksi katsayısının pozitif ve anlamlı bulunması piyasa faaliyetlerini destekleyici regülasyonların ekonomik performansı olumlu etkilediğini ortaya koymuştur.

\section{Sonuç}

$\mathrm{Bu}$ çalışmada; Mankiw, Romer ve Weil modelinde sunulan ekonomik büyümenin belirleyicilerine regülasyonların dahil edilmesi ile elde edilen model arac1lığıyla ekonomik performans ve regülasyonlar arasındaki ilişki ortaya konulmaya çalışılmıştır. Modelin regülasyonları içermesi noktasında; ekonomik birimler rin kararlarını doğrudan kısıtlayıcı müdahaleyi ifade eden kredi, emek ve reel piyasa regülasyonları endeksi ve piyasanın etkin çalışmasını sağlamaya yönelik piyasa yanlısı regülasyonları temsil eden mülkiyet haklarının korunması ve hukuki yapı endeksi değişkenleri kullanılmıştır. Bu model regülasyonların ekonomik performans üzerindeki etkisini ampirik olarak araştırmak için kullanılmıştır. Ampirik analiz için dinamik panel veri modellerinden yararlanılmıştır.
Yapilan analizler sonucunda, ekonomik birimlerin yani piyasa oyuncularının kararlarını kısıtlayan ve piyasaya doğrudan müdahale sayılabilecek regülasyonların yani kredi, emek ve reel piyasa regülasyonları endeksinin ekonomik performans üzerinde negatif bir etkiye sahip olduğu sonucuna ulaşılmıştır. Bunun yanında, piyasanın etkin çalışması için gerekli ortamın tesis edilmesine yönelik piyasa yanlısı regülasyon uygulamalarının yani mülkiyet haklarının korunması ve hukuki yapı endeksi büyüme üzerinde pozitif bir etkiye sahip olduğu sonucu analizlerle ortaya konulmuştur. Yani, piyasanın etkin çalışmasını sağlamaya odaklı ve bu ortamın tesis edilmesine yönelik yapılan regüle edici faaliyetler ekonomik büyümeyi olumlu etkileyecektir.

Sonuç olarak, bilgi asimetrisi ve eksik bilgi sorunu önemli bir problem olarak karşımıza çıkmaktadır. Devlet tarafından uygulamaya konulan regülasyonlar bilgi asimetrisinden kaynaklı olarak etkin sonuçlar ortaya koyamamaktadır. Dolayısıyla devlete göre daha fazla bilgi sahibi piyasa oyuncularının faaliyetleri sonucu müdahale gerekmeden piyasa dengeye ulaşacaktır. Devlete düşen rol burada piyasa güçlerinin etkin işlemesini sağlayacak piyasa yanlısı faaliyetlerdir. Bunlar da etkin işleyen bir hukuk sisteminin tesisi ve mülkiyet haklarının korunmasıdır. Devlet mülkiyet haklarını korur, hukuku üstün kılar ve sözleşmeler hukuksal garanti altına alınırsa piyasa oyuncularının faaliyetleri sonucunda piyasa dengeye gelecek ve herhangi bir kısitlayıcı müdahaleye ihtiyaç kalmayacaktır. Bununla birlikte, hukukun üstün kılınması ve ekonomik birimlerin sahip olduğu mülkiyet haklarının korunması ve sözleşmelerin hukuksal güvence altında olması alım-satım konusunda da özgürlüklerinin tam sağlanması anlamına gelecek ve bu durumda ekonominin performansını olumlu etkileyecektir. Sözleşme hukukuna olan güven piyasada faaliyet gösteren ekonomik birimleri iş yapma konusunda cesaretlendirecektir. Piyasa yanlısı bu regülasyonlar ekonomik büyümenin kilit faktörü olan girişimci faaliyetleri de artıracaktır ve bunun sonucunda piyasada girişimciler arasında ortaya çıkacak rekabet verimlilik artışına sebep olacaktır. Verimlilik artışı ise ekonomik büyümeyi pozitif etkileyecektir. 


\section{Kaynakça}

Acemoglu, D. (2009). Introduction to modern economic growth. USA: Princeton University Press.

Arellano, M. ve Bond, S. (1991). Some tests specification for panel data: monte carlo evidence and an application to employment equations. The Review of Economic Studies, 58(2), 277-297.

Arellano, M. ve Bover, O. (1995). Another look at the instrumental variable estimation of error-components models. Journal of Econometrics, 68, 29-51.

Baltagi, B. (2008). Econometric analysis of panel data (4. Bask1). Great Britain: John Wiley Publication.

Barro, R. J. ve Lee, J. W. (2010). A new data set of educational attainment in the World, 1950-2010. NBER Working Paper Series, No. 15902, 1-42.

Bond, S. R., Hoeffler, A. ve Temple, J. (2001). GMM estimation of empirical growth models. CEPR Discussion Papers, No.3048, 1-33.

Clauge, C., Keefer, P., Knack, S. ve Olson, M. (1999). Contract-intensive money: contract enforcement, property rights, and economic performance. Journal of Economic Growth, 4, 185-211.

Dawson, J. W. (2006). Regulation, investment and growth across countries. Cato Journal, 26(3), 489-509.

De Serres, A., Kobayakawa, S., Slok, T. ve Vartia, L. (2006). Regulation of financial systems and economic growth in OECD countries: an empirical analysis. OECD Economic Studies, No:43, 77-113.

Djankov, S., Mc Liesh, C. ve Ramalho, R. M. (2006). Regulation and growth. Economics Letters, 92(3), 395-401.

Greene, W. (2012). Econometric analysis (7.bask1). USA: Pearson Education Publication.

Gwartney, J, Lawson, R. ve Hall, J. (2012). Economic freedom of the world. Canada: Fraser Institute.

Heston, A., Summers, R. ve Aten, B. (2012). Penn world table version 7.1. Center for International Comparisons of Production, Income and Prices at the University of Pennsylvania
Mankiw, N. G.; Romer, D. ve Weil, D.N. (1992). A contribution to the empirics of economic growth. The Quarterly Journal of Economics, 107(2), 407-437.

Jalilian, H., Kirkpatrick, C. ve Parker, D. (2007). The impact of regulation on economic growth in developing countries: a cross-country analysis. World Development, 35(1), 87-103.

Jorgenson, D. W. ve Wilcoxen, P. J. (1990). Enviromental regulation and U.S. economic growth. The Rand Journal of Economics, 21(2), 314-340.

Koedijk, K., Kremers, J., David, P. ve Röller, L.-H. (1996). Market opening, regulation and growth in Europe. Economic Policy, 11(23), 443-467.

Krol, R. ve Svorny, S. (1994). Regulation and economic performance: lessons from the states. Cato Journal, 14(1), 55-64.

Levine, R. (1999). Law, finance and economic growth. Journal of Financial Intermediation, 8 (1-2), 8-35.

Loayza, N. V., Oviedo, A. M. ve Serven, L. (2005). The impact of regulation on growth and informality: cross-country evidence. World Bank Policy Research Working Paper, No. WPS3623.

Mankiw, N. G.; Romer, D. ve Weil, D.N. (1992). A contribution to the empirics of economic growth. The Quarterly Journal of Economics, 107(2), 407437.

Nonneman, W. ve Vanhoudt, P. (1996). A further augmentation of the Solow model and the empirics of economic growth for OECD countries. The Quarterly Journal of Economics, 111(3), 943-953.

Roodman, D. (2009). How to do xtabond2: an introduction to difference and system gmm in stata. The Stata Journal, 9(1), 86-136.

Solow, R.M. (1956). A Contribution to the theory of economic growth. The Quarterly Journal of Economics, 70(1), 65-94.

Tatoğlu, F. Y. (2012). İleri panel veri analizi. İstanbul: Beta Yayıncilık. 